\title{
Epidermodysplasia Verruciformis: A Case Report
}

\author{
Joshi $A^{1}$, Amatya $B^{2}$
}

${ }^{1}$ Resident, ${ }^{2}$ Lecturer, Department of Dermatology and Venereology, Nepal Medical College Teaching Hospital, Attarkhel, Gokarneshwor, Kathmandu, Nepal

\begin{abstract}
Epidermodysplasia verruciformis (EDV) is a rare, inherited disorder that is characterized by an increased susceptibility to infection with specific human papilloma viruses (HPV) and a greater propensity for developing malignant skin tumors.

A 26 years old Nepalese male patient presented with complaints of multiple asymptomatic raised warty lesions on bilateral hands and multiple light colored flat to raised lesions present over the neck, trunk, bilateral extremities sparing the face and genitals. A skin biopsy was performed which revealed hyperkeratosis, focal parakeratosis, acanthosis. Keratinocytes were swollen, nuclei were large, round and empty with marginal distribution of chromatin.

Epidermodysplasiaverruciformis is a rare inherited disorder spread by HPV. It is characterized by hypopigmented or hyperpigmented macular lesions, pityriasis versicolor-like lesions and an early tendency to develop skin malignancies. The management of EDV includes early diagnosis, sun protection, life-long observation for the malignant transformation and therapeutic modalities like acitretin, imiquimod, topical retinoids, cryotherapy, etc.
\end{abstract}

Key words: Epidermodysplasia Verruciformis; Papillomavirus Infections; Warts

\section{Introduction}

E pidermodysplasiaverruciformis(EDV) is a rare disease characterized by susceptibility to infections caused by human papillomaviruses (HPV) specifically HPV 5, 8, 9, 12, 14, 15, 17, $19-25$ and due to defect in cell mediated immune response. ${ }^{1}$ The skin lesions start in childhood and are predominantly seen in the sun exposed sites. ${ }^{2}$ Lesions can present as widespread skin eruptions of flat to papillomatous wart-like lesions and reddish brown pigmented plaque on the trunk, extremities and face, and can also present as pityriasis versicolor-like lesions. ${ }^{3}$ There is high risk of developing cutaneous squamous cell carcinomas (SCC) in early adult life. $^{2}$

\section{Case report}

A 26 years old Nepalese male patient presented to dermatology outpatient department (OPD) with

Financial disclosure: None.

Conflict of interest to disclosure: None declared.

Address of Correspondence

Dr. Anisha Joshi

Resident

Department of Dermatology

Nepal Medical College

Kathmandu, Nepal.

E-mail: janishia27@yahoo.com complaints of multiple asymptomatic raised warty lesions on the bilateral hands and multiple light colored flat to raised lesions present over the neck, trunk, and bilateral extremities sparing the face and genitals for 10 years. These lesions were few at the beginning and were first noticed over the hands. There was gradual increase in the number of lesion. He had not taken any medication for this condition. There was no history suggestive of tuberculosis, diabetes, heart disease or thyroid disease. He was not on any medication prior to the development of the lesions. There was no similar history in any family members. A serological examination did not reveal the presence of syphilis, hepatitis B, hepatitis C or HIV.

Submitted: $26^{\text {th }}$ October 2019

Accepted: $5^{\text {th }}$ December 2019

Published: $7^{\text {th }}$ October 2020

How to cite this article

Joshi A, Amatya B. Epidermodysplasia verruciformis: A case report. Nepal Journal of Dermatology Venereology and Leprology. 2020;18(1):60-3. https://doi.org/10.3126/njdvl. v18i1.26127.

\section{(c) (i)}

Licensed under CC BY 4.0 International License which permits use, distribution and reproduction in any medium, provided the original work is properly cited. 
On examination, there were multiple verrucous plaques over the dorsal hands, size ranged from $0.5-2 \mathrm{~cm}$, round to oval, rough surface with normal surrounding areas. (Figure 1. A, B) There were multiple hypopigmented macules and plaque over the preauricular, postauricular region, jawline, neck, trunk, bilateral arms, forearms, thighs, legs and dorsal aspect of feet. The size ranged from $0.25-1.5 \mathrm{~cm}$, round to oval, smooth surface with normal surrounding areas. (Figure 2. A,B) Hair, nail and mucous membrane were not involved. Systemic examination was normal. There were no abnormalities detected on examination of higher mental function.

A skin biopsy was performed which revealed hyperkeratosis, focal parakeratosis and acanthosis. There was also increase in melanocytes in basal layer.
Most of the keratinocytes were swollen and irregularly shaped. They had abundant basophilic cytoplasm and contained numerous round basophilic keratohyaline granules. Nuclei were large, round and empty with marginal distribution of chromatin, some were pyknotic. Dermis showed mild lymphocytic infiltration in the perivascular region. (Figure 3. A,B)

Based on the clinical and histopathological examination, a provisional diagnosis of EDV was made. We ruled out verruca vulgaris as histopathology did not reveal papillomatosis, elongated rete ridges and koilocytes. ${ }^{5}$ Similarly, Acrokeratosis verruciformis of Hopf was excluded as hypergranulosis, papillomatosis, resembling church spires and elongated rete ridges were absent on histopathology. ${ }^{6}$

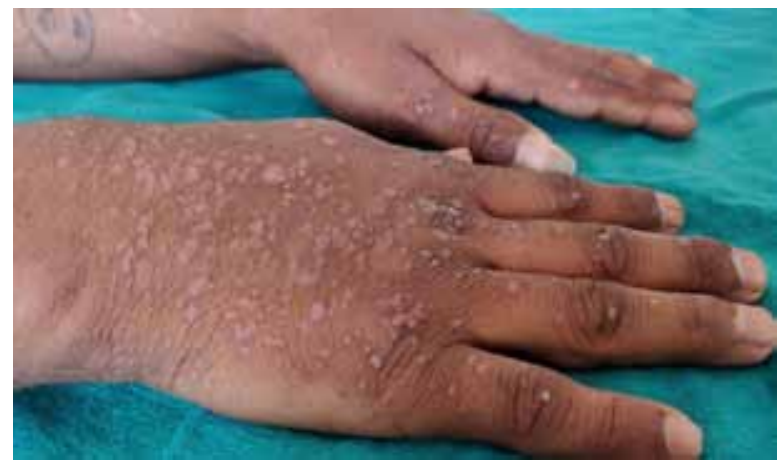

(B)

(A)

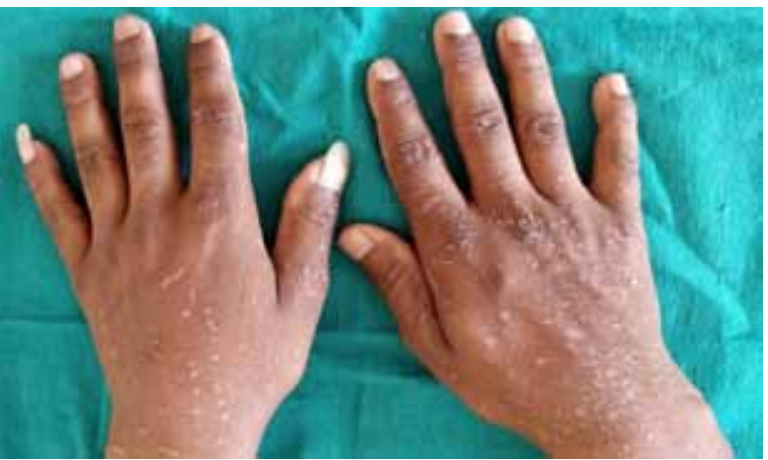

Figure 1 ( $\mathrm{A}$ and $\mathrm{B})$ : Multiple warty plaques over the dorsal aspect of the bilateral hands
(A)

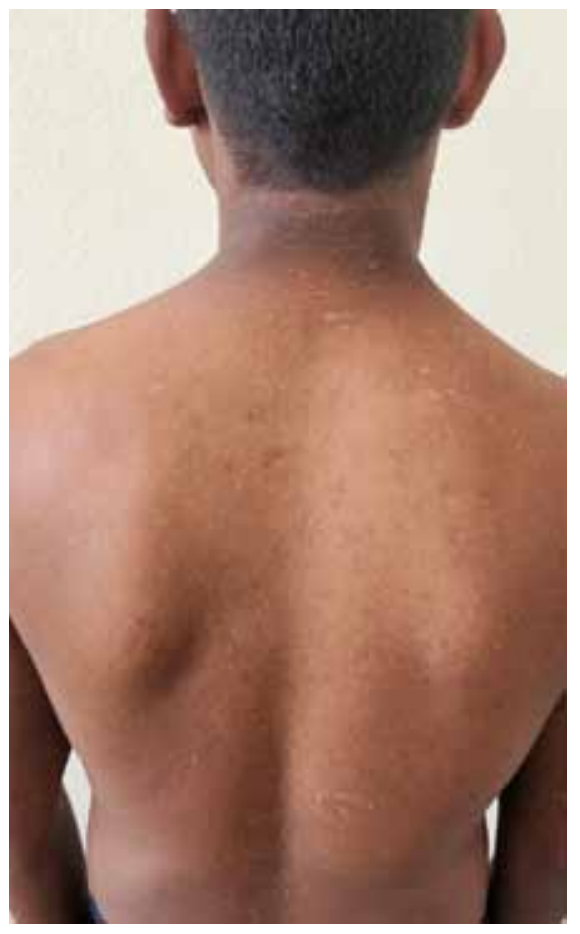

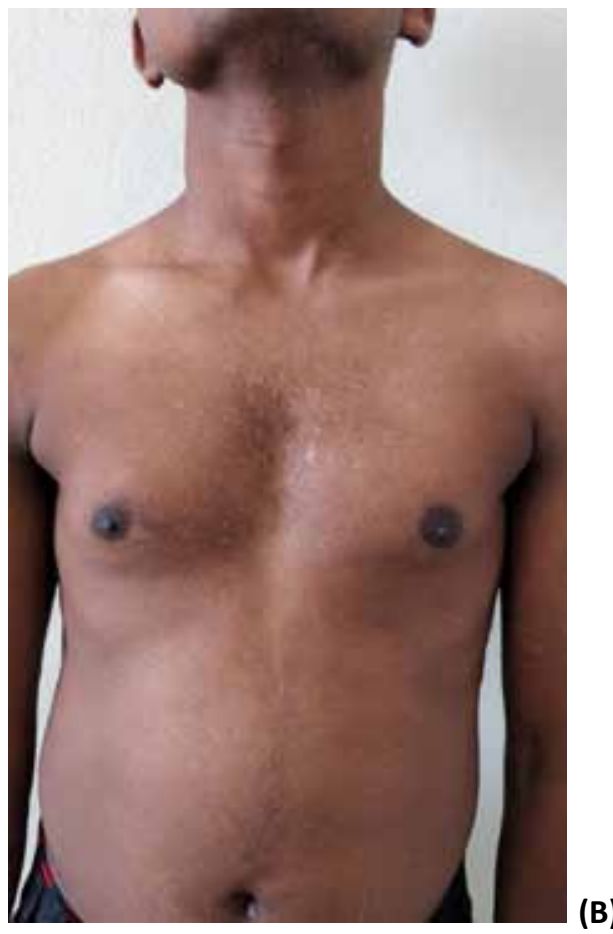

(B)

Figure $\mathbf{2}$ ( $\mathbf{A}$ and $\mathbf{B}$ ): Multiple hypopigmented macules present over the chest, abdomen and back 
The patient was advised sun protection. The treatment plan was oral acitretin and imiquimod for approximately six months and to be followed up monthly. But due to unavailability of these medicines, the treatment plan could not be carried out. However, the patient is being followed up at regular intervals to detect malignant transformation if any at an early stage.

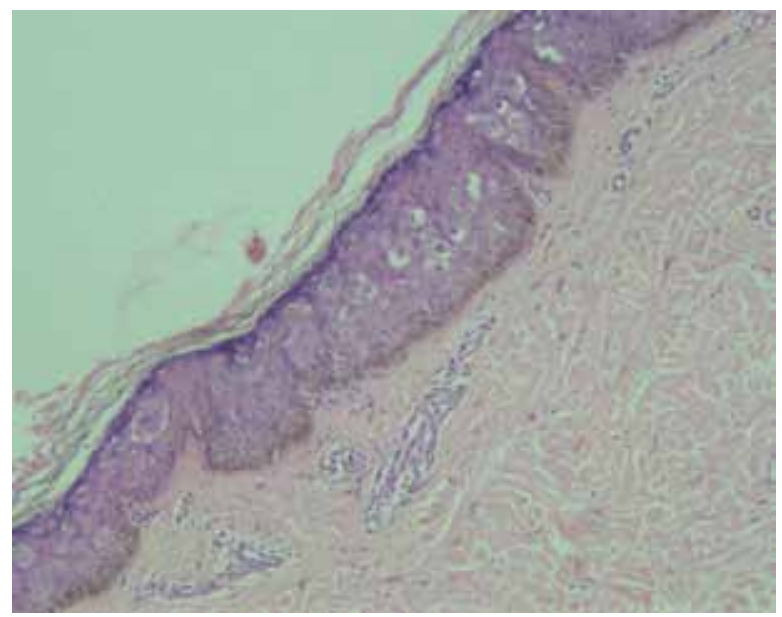

(A)

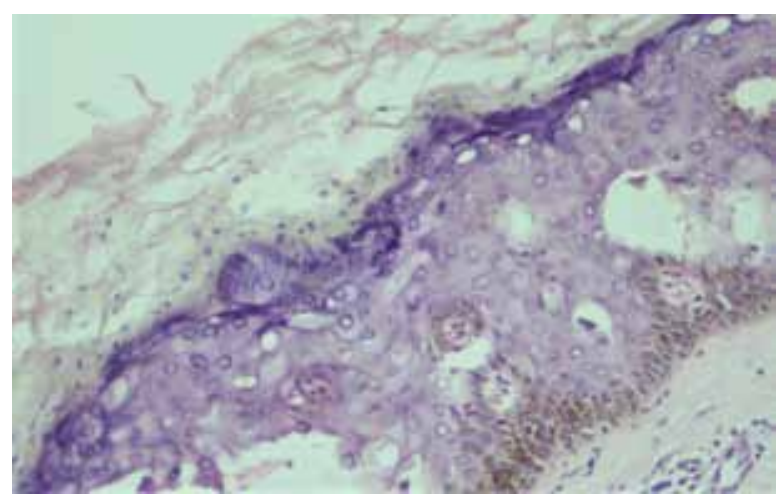

(B)

Figure 3 (A): H \& E stain, 10X. Histopathology shows hyperkeratosis, focal parakeratosis and acanthosis. There is abundant basophilic cytoplasm and numerous round basophilic keratohyaline granules in the keratinocytes.

(B): H \& E stain, 20X. Histopathology showsvacuolation in perinuclear area of keratinocytes.

\section{Discussion}

Epidermodysplasiaverruciformis, first described by Lewandowski and Lutz in 1922,is a rare, lifelong disorder of cell mediated immunity (CMI) with no sex, racial or geographic predisposition and is inherited in an autosomal recessive fashion. ${ }^{1,4}$ The gene involved are EVER1 (Epidermodysplasia Verruciformis Enhancing Region) and EVER2. Mutation in these gene causes an individual to be susceptible to develop EDV. Mutation in genes and infection by HPV14, HPV20, HPV21 and HPV25 is usually associated only with the development of benign lesions while HPV5, HPV8, HPV10 and HPV47 were found in more than $90 \%$ of EV-associated malignant neoplasms. ${ }^{4}$

It comprises of flaking or hyperkeratotic skin lesions predominantly in sun-exposed sites presenting in childhood. Pityriasis versicolor-like lesions and wartlike lesions can also present.The histopathological features are hyperkeratosis, acanthosis, vacuolation in perinuclear area of keratinocytes which involves the upper half of three fourth of the spinous layer. Classic clear cells are not found in all lesions. ${ }^{2}$ There is a high risk of development of cutaneous squamous cell carcinomas in early adult life. ${ }^{2}$

Treatment for EDV includes strict sun avoidance. Systemic and topical retinoids, interferon, immunotherapy, electrodessication and cryotherapy are the treatment modalities for EDV. ${ }^{4}$ However, there is no definitive therapy for EDV. Early diagnosis, sun protection, life-long observation for the malignant transformation and excision of the cancerous lesions are imperative for better survival. ${ }^{4} A s$ the treatment options (acitretin and imiquimod) are not available in any part of Nepal, our patient was deprived of proper treatment. It would be helpful if the Ministry of Health and Population (MoHP), Nepal government could procure these medications for the benefit of patient.

\section{References}

1. De Sa NB, Barbato MT, Nunes DH, Guerini MB, Giunta GD. Epidermodysplasiaverruciformis: clinical presentation with varied forms of lesions. An Bra Dermatol 2011; 86: S57-60. https://doi. org/10.1590/S0365-05962011000700014

2. Sterling JC. Viral infections. In: Griffiths $C$, Barker J, Bleiker T, Chalmers R, Creamer D, editors.

Rook's textbook of Dermatology, 9th ed. London; Wiley Blackwell, 2010.p. 25.59-61.

3. Sharma S, Barman KD, Sarkar R, Manjhi M, Garg VK. Efficacy of oral zinc therapy in epidermodysplasiaverruciformis with squamous cell carcinoma. Indian Dermatol Online J2014; 5: 55-58. https://doi.org/10.4103/22295178.126034 
4. Sharma S, Fouzia S, Singh A. Epidermodysplasia verruciformis: three case reports and a brief review. Acta dermatovenerol 2017; 26: 59-61. https://doi.org/10.15570/actaapa.2017.19

5. Xu X, Erickson L, Yun SK, Chen L. Diseases caused by viruses. In: Elder DE, Elenitsas $R$, Rosenbach M, Murphy GE, Rubin Al, Xu X, editors. Lever's
Histopathology of the Skin, 11thed. China; Wolters Kluwer, 2015.p. 796-8.

6. Arkin L, Lee LW, Rubin Al, Yan AC. Congenital Diseases (Genodermatoses). In: Elder DE, Elenitsas R, Rosenbach M, Murphy GE, Rubin Al, $\mathrm{Xu} X$, editors. Lever's Histopathology of the Skin, 11thed. China; Wolters Kluwer, 2015.p.163-4. 